\title{
Image-guided combined ablation and resection in thoracic surgery for the treatment of multiple pulmonary metastases: A preliminary case series
}

\author{
Oliver J. Harrison, MD, ${ }^{\mathrm{a}}$ Sajiram Sarvananthan, MRCS, ${ }^{\mathrm{a}}$ Alessandro Tamburrini, MD, ${ }^{\mathrm{a}}$
} Charles Peebles, FRCR, ${ }^{b}$ and Aiman Alzetani, MD $^{\mathrm{a}}$

\section{ABSTRACT}

Objectives: To demonstrate the feasibility and preliminary outcomes of a nove hybrid technique combining percutaneous microwave ablation and wire-assisted wedge resection for patients with multiple pulmonary metastases using intraoperative imaging.

Methods: We describe our technique and present a retrospective case series of 4 patients undergoing iCART at our institution between August 2018 and January 2020. Procedures were performed in a hybrid operating suite using the ARTIS Pheno cone beam computerized tomography scanner (Siemens Healthineers, Erlangen, German). Patient information included past history of malignancy as well as lesion size, depth, location, and histology result. Surgical complications and length of stay were also recorded.

Results: Five procedures were performed on 4 patients during the study period. One patient underwent bilateral procedures 4 weeks apart. All patients underwent at least 1 ablation and 1 wedge resection during the combined procedure. Patient ages ranged from 40 to 66 years and the majority $(75 \%)$ were men. All had a past history of cancer. Lesions were treated in every lobe. Size and depth ranged from 6 to $24 \mathrm{~mm}$ and 21 to $33 \mathrm{~mm}$, respectively, for ablated nodules and 5 to $27 \mathrm{~mm}$ and o to $22 \mathrm{~mm}$, respectively, for the wedge resected nodules. Three procedures were completed uniportal and operative time ranged from 51 to $210 \mathrm{mi}-$ nutes. All cases sustained $<10 \mathrm{~mL}$ blood loss. There were 2 intraoperative pneumothorax, 1 prevented successful completion of the ablation. One patient required a prolonged period of postoperative physiotherapy and was discharged on day 6 . The other patients were discharged on postoperative day 2 or 3 . All 5 histology specimens confirmed metastatic disease.

Conclusions: Our hybrid approach provides a minimally invasive and comprehensive personalized therapy for patients with multiple pulmonary metastases under a single general anesthetic. It provides histology-based diagnosis whilst minimizing lung tissue loss and eliminating the need for transfer from radiology to operating theatre. Emergence of ablation as a treatment for stage 1 non-small cell lung cancer and the expansion of lung cancer screening may widen the application of iCART in the future. (JTCVS Techniques 2021;9:156-62)

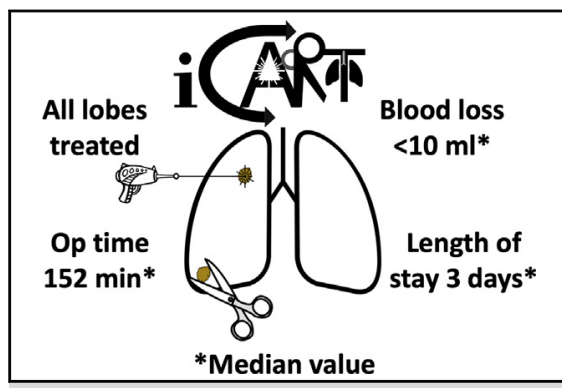

Combined ablation and resection to treat multiple pulmonary metastases in 1 operation.

CENTRAL MESSAGE

ICART is a novel, minimally inva-

sive, personalized treatment

strategy for patients with multi-

ple pulmonary metastases

combining lung tissue-sparing microwave ablation and diag-

nostic wedge resection.

\section{PERSPECTIVE}

iCART is a personalized treatment strategy for patients with multiple pulmonary metastases, combining diagnostic wedge resection and tissue-sparing ablation. It allows treatment of multiple nodules in a single anesthetic without the need for transfer from radiology. Emergence of ablation for treating stage 1 lung cancer and lung cancer screening may widen the application of iCART in the near future.

See Commentaries on pages 163 and 165 .
From the Departments of ${ }^{\mathrm{a}}$ Thoracic Surgery and ${ }^{\mathrm{b}}$ Cardiothoracic Radiology, University Hospital Southampton, Southampton, United Kingdom.

Read at The American Association for Thoracic Surgery International Thoracic Surgical Oncology Summit: A Virtual Learning Experience, October 16-17, 2020.

Received for publication March 9, 2021; accepted for publication March 10, 2021; available ahead of print March 13, 2021
Address for reprints: Oliver J. Harrison, MD, Department of Thoracic Surgery, Southampton General Hospital, Mailpoint 46, Tremona Rd, Southampton, SO16 6YD, United Kingdom (E-mail: ojharrison@ doctors.org.uk). 2666-2507

Copyright (c) 2021 The Author(s). Published by Elsevier Inc. on behalf of The American Association for Thoracic Surgery. This is an open access article under the CC BY-NC-ND license (http://creativecommons.org/licenses/by-nc-nd/4.0/). https://doi.org/10.1016/j.xjtc.2021.03.013 


\section{Abbreviations and Acronyms \\ GGO = ground-glass opacity \\ iCART $=$ image-guided combined ablation and resection in thoracic surgery \\ iVATS $=$ image-guided video-assisted thoracoscopic surgery \\ pMWA $=$ percutaneous microwave ablation \\ RFA = radiofrequency ablation}

Video clip is available online.

The incidence of metastasis in the lung is second only to the liver and failure to treat these in a timely manner can lead to respiratory failure and death. Chemotherapy forms the mainstay of treatment for pulmonary metastasis and the efficacy of both immunotherapy and molecular-targeted personalized therapies continues to improve. However, patient response is variable and side-effects are common. ${ }^{1,2}$

Surgical metastatectomy by wedge resection has long been established as safe and potentially curative procedure for pulmonary metastases. ${ }^{3}$ More recently, percutaneous ablation has been demonstrated as a safe alternative, particularly for small, deep nodules that may otherwise require major lung resection. ${ }^{4}$ Percutaneous microwave ablation (pMWA) is increasingly favored due to its superior characteristics versus radiofrequency ablation (RFA) ${ }^{5,6}$ However, peripheral ground-glass opacities (GGOs) can be difficult to palpate and may not be suitable for pMWA due to proximity to the chest wall and risk of chest pain, pleural effusion, and pneumothorax with bronchopleural fistula. ${ }^{7}$ Image-guided video-assisted thoracoscopic surgery (iVATS) using localization techniques can facilitate removal of such lesions. ${ }^{8}$

Complex patterns of multiple pulmonary metastases demand an equally sophisticated personalized therapy tailored to each individual patient. Image-guided combined ablation and resection in thoracic surgery (iCART) was developed to treat multiple pulmonary metastases in a single general anesthetic without the need to transfer the patient from the radiology department. We present the technique and preliminary outcomes of iCART for managing for multiple pulmonary metastases.

\section{METHODS \\ Patient Selection}

Institutional review board approval was granted for this study (ZAUD ID 6778). Where patient images or video are included, informed written consent was obtained in accordance with our institutional requirements. Retrospective review of case notes for all patients undergoing iCART for multiple pulmonary metastases performed between August 2018 and

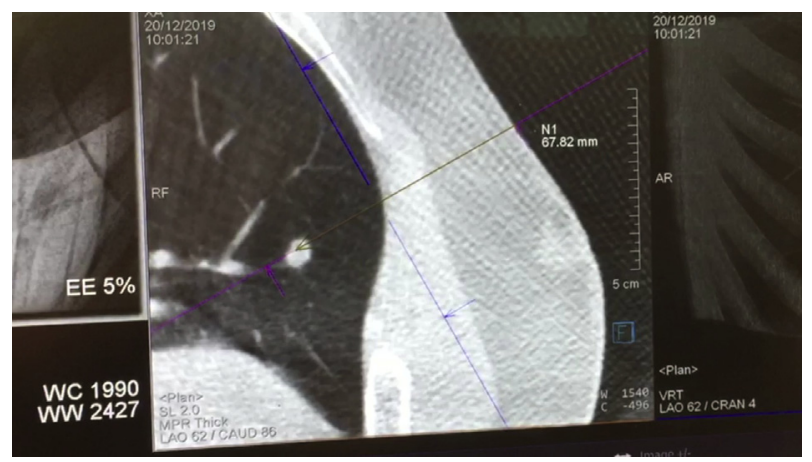

VIDEO 1. A video clip demonstrating image-guided combined ablation and resection of two pulmonary nodules in a 40-year-old man with a previous history of adenocarcinoma. Video available at: https://www.jtcvs. org/article/S2666-2507(21)00244-3/fulltext.

January 2020 was undertaken. Patients were selected for iCART if they had $\geq 2$ pulmonary metastases as dictated by past history of malignancy and the opinion of the lung cancer multidisciplinary team. Procedures were performed in the hybrid operating suite at our institution using the ARTIS Pheno (Siemens Healthineers, Erlangen, Germany) cone beam computed tomography scanner. Patient information included a past history of malignancy, lesion size, depth, location, and histological result. Operative time was calculated from the start of the first scan to completion of skin incision closure. Surgical complications and length of stay were also recorded.

\section{Surgical Technique}

A brief video demonstration of the surgical technique is shown in Video 1. An appropriate case was first identified by the lung cancer multidisciplinary team (Figure 1). Following induction of general anesthesia, a dual-lumen endotracheal tube is inserted and the patient is placed in the lateral position with the operating side facing up. Care is taken to ensure all tubing and monitoring lines are clear of the rotatory path of the Carm of the cone beam computed tomography scanner. An initial scan is performed (Figure 2, A), the lesion for ablation is located and a path is mapped from the skin surface to the lesion on the image software (Figure 2, B). The Neuwave percutaneous microwave ablation system (Johnson \& Johnson, Franklin Lakes, NJ) is used and a probe is passed under laser guidance into the lesion (Figure 2, C). Correct positioning is confirmed with a further scan and then microwave energy is delivered to the lesion (typically 60 Watts for 5 minutes). Once the ablation is complete, the probe is left in place and a further scan is performed to confirm the position of the lesion to be wedge resected. A path to this lesion is plotted as for the ablation, and a Somatex Lung Marker System (Somatex Medical Technologies, Berlin, Germany) guidewire is passed under laser guidance and the correct position again confirmed (Figure 2,D). Uniportal VATS is then performed and the lesion is resected using an endostapler with the guidewire in situ (Figure 2, $E)$. The specimen is removed and presence of the lesion is confirmed before sending to histopathology (Figure 2, F). A chest tube is placed and the patient is recovered and sent to the thoracic surgical ward for observation.

\section{RESULTS}

Five procedures were performed on 4 participants during the study period (see Table 1). One patient underwent bilateral procedures 4 weeks apart. All patients underwent at least 1 ablation and 1 wedge resection during the combined procedure, 1 patient had 2 wedge resections. Patient age ranged from 40 to 66 years and the majority $(75 \%)$ of the 

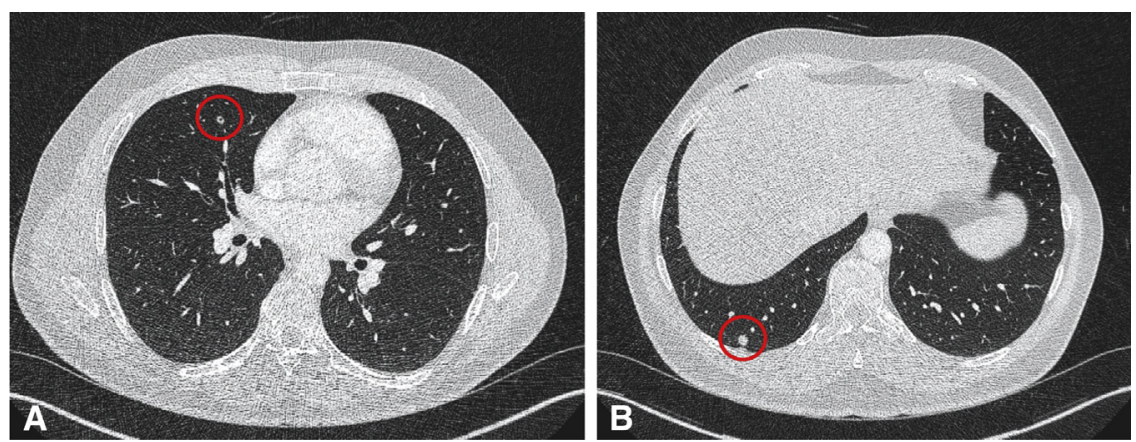

FIGURE 1. Surveillance chest computed tomography scan of patient 3, a 40-year-old man with previous history of colorectal adenocarcinoma who was found to have 2 new pulmonary nodules suspicious for lung metastasis. A, Axial slice of the deeper, smaller right middle lobe nodule that is planned for ablation. B, Axial slice of the more peripheral, larger right lower lobe nodule that is planned for wedge resection. This corresponds to patient 3 in Table 1.

patients were men. All had a past history of cancer (eg, adrenal adenocarcinoma, osteosarcoma, rectal adenocarcinoma, and breast adenocarcinoma). Lesions were treated in every lobe. In general, patients had 1 or more superficial lesions suitable for wedge resection (small or nonsolid favor iVATS) and 1 or more deep lesions ( $>2 \mathrm{~cm}$ depth) for ablation (for which conventional wedge resection would require removal of a large volume of normal tissue). Three procedures were completed via uniportal, 1 biportal, and 1 triportal. All cases sustained $<10 \mathrm{~mL}$ blood loss (see Table 2). There were 2 intraoperative pneumothorax, 1 prevented successful completion of the ablation. One patient

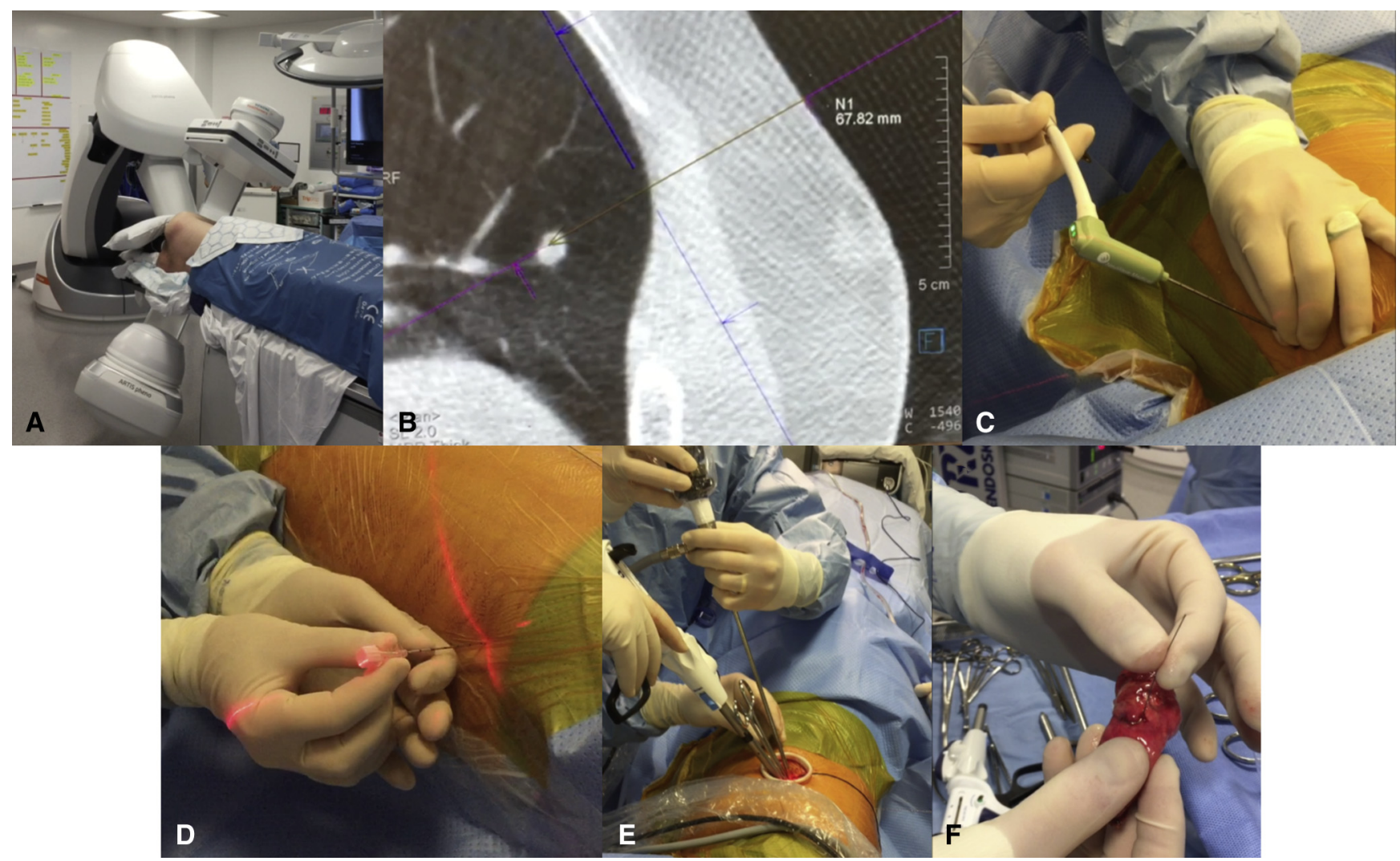

FIGURE 2. Intraoperative images of the imaged-guided combined ablation and resection procedure. A, The anaesthetized patient is positioned in the hybrid operating room and an initial scan is performed with the ARTIS Pheno (Siemens Healthineers, Erlangen, Germany) cone-beam computerized tomography scanner. B, The nodule of interest is localized and a virtual path plotted from the skin using the software package. C, The ablation probe is inserted using the predetermined path with the assistance of a laser guide mounted on the C-arm. D, For the lesion to be resected, a wire is passed under laser guidance using a predetermined path overlaid on intra-operative imaging. E, Uniportal video-assisted thoracoscopic wedge resection of the nodule localized with wireassistance is performed using an endoscopic stapler. F, The wedge resected specimen containing the lesion and the localization wire is seen. 
TABLE 1. Patient and lesion data

\begin{tabular}{|c|c|c|c|c|c|c|c|c|c|c|c|c|c|}
\hline \multirow[b]{2}{*}{$\begin{array}{c}\text { Patient } \\
\text { ID }\end{array}$} & \multirow[b]{2}{*}{$\begin{array}{c}\text { Age } \\
(\mathbf{y})\end{array}$} & \multirow[b]{2}{*}{ Gender } & \multicolumn{3}{|c|}{ Wedge 1} & \multicolumn{3}{|c|}{ Wedge 2} & \multicolumn{5}{|c|}{ Ablation 1} \\
\hline & & & Location & $\begin{array}{c}\text { Size } \\
(\mathbf{m m})\end{array}$ & $\begin{array}{l}\text { Depth } \\
\text { (mm) }\end{array}$ & Location & $\begin{array}{c}\text { Size } \\
(\mathbf{m m})\end{array}$ & $\begin{array}{l}\text { Depth } \\
\text { (mm) }\end{array}$ & Location & Size $(\mathbf{m m})$ & $\begin{array}{r}\text { Depth } \\
\text { (mm) }\end{array}$ & $\begin{array}{l}\text { Time } \\
\text { (min) }\end{array}$ & $\begin{array}{c}\text { Power } \\
\text { (Watts) }\end{array}$ \\
\hline $1 a^{*}$ & 54 & $\mathrm{M}$ & LLL & 25 & 0 & & & & LUL & 24 & 30 & 14 & 60 \\
\hline $1 b^{*}$ & & & RUL & 16 & 6 & RLL & 27 & 0 & RUL & 6 & 33 & 7 & 60 \\
\hline 2 & 59 & M & LUL & 10 & 12 & & & & LLL & 7 & 33 & & \\
\hline 3 & 40 & M & RLL & 8 & 5 & & & & RML & 6 & 21 & 10 & 55 \\
\hline 4 & 66 & $\mathrm{~F}$ & LUL & 5 & 22 & & & & LUL & 10 & 27 & 5 & 55 \\
\hline
\end{tabular}

$M$, Male; $L L L$, left lower lobe; $L U L$, left upper lobe; $R U L$, right upper lobe; $R L L$, right lower lobe; $R M L$, right middle lobe; $F$, female. *Patient 1 underwent 2 procedures (1a and $1 \mathrm{~b})$.

required a prolonged period of postoperative physiotherapy and was discharged on postoperative day 6 . All 5 histological specimens confirmed metastatic disease. At a maximum follow-up of 24 months (median 11 months), there was no recurrence. Follow-up imaging for patient 3 is demonstrated in Figure 3.

\section{DISCUSSION}

In patients presenting with multiple pulmonary metastases, staged procedures have historically been performed. The potential risk of this strategy is interim disease progression and subjecting the patient to multiple general anesthetics. Similarly, in the absence of a hybrid surgical suite with intraoperative imaging, the patient must be transferred from the radiology department to an operating room, which may risk dislodgement of localizing devices, discomfort for the patient, or anesthetic complications. ${ }^{9}$ To the best of our knowledge, this is the first report of combined percutaneous ablation and wire-assisted VATS wedge resection using image-guidance for the treatment of multiple pulmonary metastases. It appears to be safe and effective from our limited early experience and combines the advantages of tissue-preserving ablation and diagnostic wedge resection. It offers a minimally invasive personalized therapy that can be tailored to the individual patient's disease (Figure 4).
Both wedge resection and ablation are demonstrated to improve survival in pulmonary metastasis, although they have never been compared in a randomized trial. ${ }^{3,10}$ Ablative techniques include cryoablation, RFA, and MWA. The majority of evidence relates to RFA; however, there is growing support for the superiority of MWA, which may have several advantages. Ablation speed is typically 3 times faster and microwave energy propagates more efficiently through air and tissue, offsetting the high intrinsic impedance of lung tissue. Similarly, tissue carbonization (which reduces thermal conduction in RFA) does not occur in MWA. Theoretically, tumor recurrence may be reduced with MWA due to reduced heat sink effect, although data supporting this is limited., ${ }^{5,6}$ With development in efficiency of ablative technology, outcomes are now comparable between wedge resection and ablation with 5 -year survivals reported at $36 \%$ to $68 \%$ and $35 \%$ to $56 \%$, respectively, for pulmonary metastases from colorectal cancer. ${ }^{11,12}$ Recurrence rates within the lung are similar after ablation and wedge resection at approximately $32 \%$ to $62 \%$ with local recurrence at the resection or ablation site quoted at $7 \%$ to $28 \%$ and $12 \%$ to $36 \%$, respectively. ${ }^{13-17}$ Recurrence is common in pulmonary metastasis and patients often require multiple interventions over their lifetime.

TABLE 2. Perioperative and follow-up data

\begin{tabular}{|c|c|c|c|c|c|c|c|}
\hline $\begin{array}{c}\text { Patient } \\
\text { ID }\end{array}$ & $\begin{array}{l}\text { Operative } \\
\text { time }(\min )\end{array}$ & $\begin{array}{c}\text { Blood } \\
\text { loss }(\mathbf{m L})\end{array}$ & $\begin{array}{c}\text { Length of } \\
\text { stay (d) }\end{array}$ & $\begin{array}{c}\text { Intra- or } \\
\text { postoperative } \\
\text { complications }\end{array}$ & Histology & $\begin{array}{c}\text { Postoperative } \\
\text { follow-up } \\
\text { interval (mo) }\end{array}$ & $\begin{array}{c}\text { Evidence of } \\
\text { residual disease } \\
\text { or recurrence }\end{array}$ \\
\hline $1 a^{*}$ & 51 & 0 & 3 & None & Metastatic adrenocortical & 24 & No \\
\hline $1 b^{*}$ & 210 & 0 & 6 & None & Metastatic adrenocortical & 22 & No \\
\hline 2 & 180 & 0 & 2 & $\begin{array}{l}\text { Pneumothorax } \\
\text { prevented ablation }\end{array}$ & Metastatic spindle cell & 3 & No \\
\hline 3 & 152 & 0 & 2 & $\begin{array}{l}\text { Pneumothorax } \\
\text { postablation, did } \\
\text { not affect wire } \\
\text { localization }\end{array}$ & Metastatic colorectal & 15 & No \\
\hline 4 & 86 & 0 & 3 & None & Metastatic breast & 2 & No \\
\hline
\end{tabular}

*Patient 1 underwent 2 procedures (1a and $1 \mathrm{~b}$ ). 

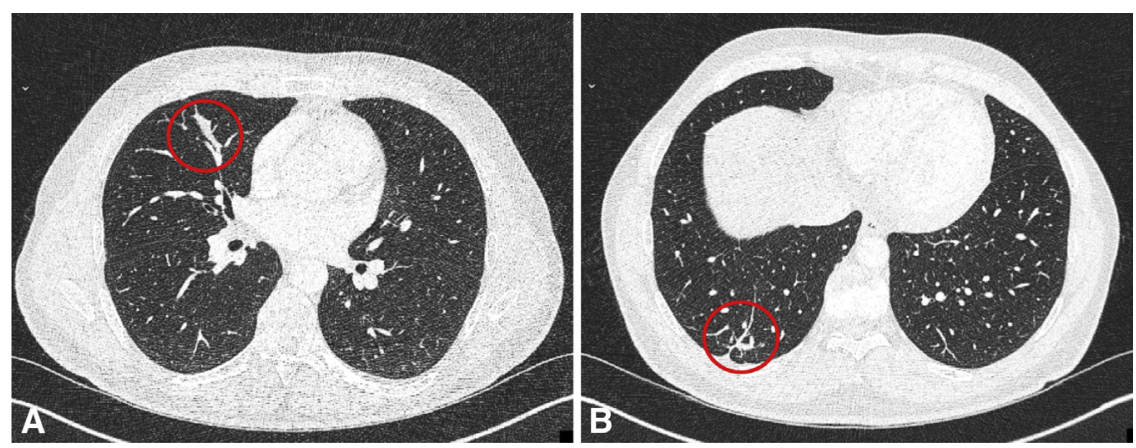

FIGURE 3. Eight-month follow-up chest computed tomography scan for patient 3 . A, axial slice at the level of the right middle lobe lesion, which has been replaced by scar tissue with normal appearances. B, Axial slice at the level of the right lower lobe lesion staple line can be seen with normal appearance. This corresponds to patient 3 in Table 1.

Because patients frequently re-present with recurrent nodules, preserving lung tissue is paramount. This is among the main advantages of pMWA: it minimizes lung tissue loss, and multiple treatment episodes may be tolerated without a significant reduction in lung volume or function. ${ }^{18}$ Another advantage of pMWA is its ability to treat deep, small nodules that would be challenging to palpate and resect by conventional wedge resection. Therefore, iCART may be particularly useful in high-risk patients where maximizing lung tissue preservation and minimizing anesthetic risk are desirable. pMWA is less suitable for peripheral nodules and those within close proximity of larger vessels or bronchi. Ablation of peripheral lesions is associated with an increased risk of postoperative pain, pleural effusion, and pneumothorax. ${ }^{17}$ As a general rule, we avoid ablation if the nodule is within $5 \mathrm{~mm}$ of the visceral pleural or within $3 \mathrm{~mm}$ of a vessel or bronchus with a diameter $>3 \mathrm{~mm}$. This is partly to avoid damaging these structures, but also to avoid subtreatment of lesions where heat sink of energy into adjacent structures may increase local recurrence. ${ }^{19}$ Ablation of large nodules is more challenging and associated with recurrence; therefore,

\section{ICART}

Image-guided combined ablation and resection in Thoracic surgery

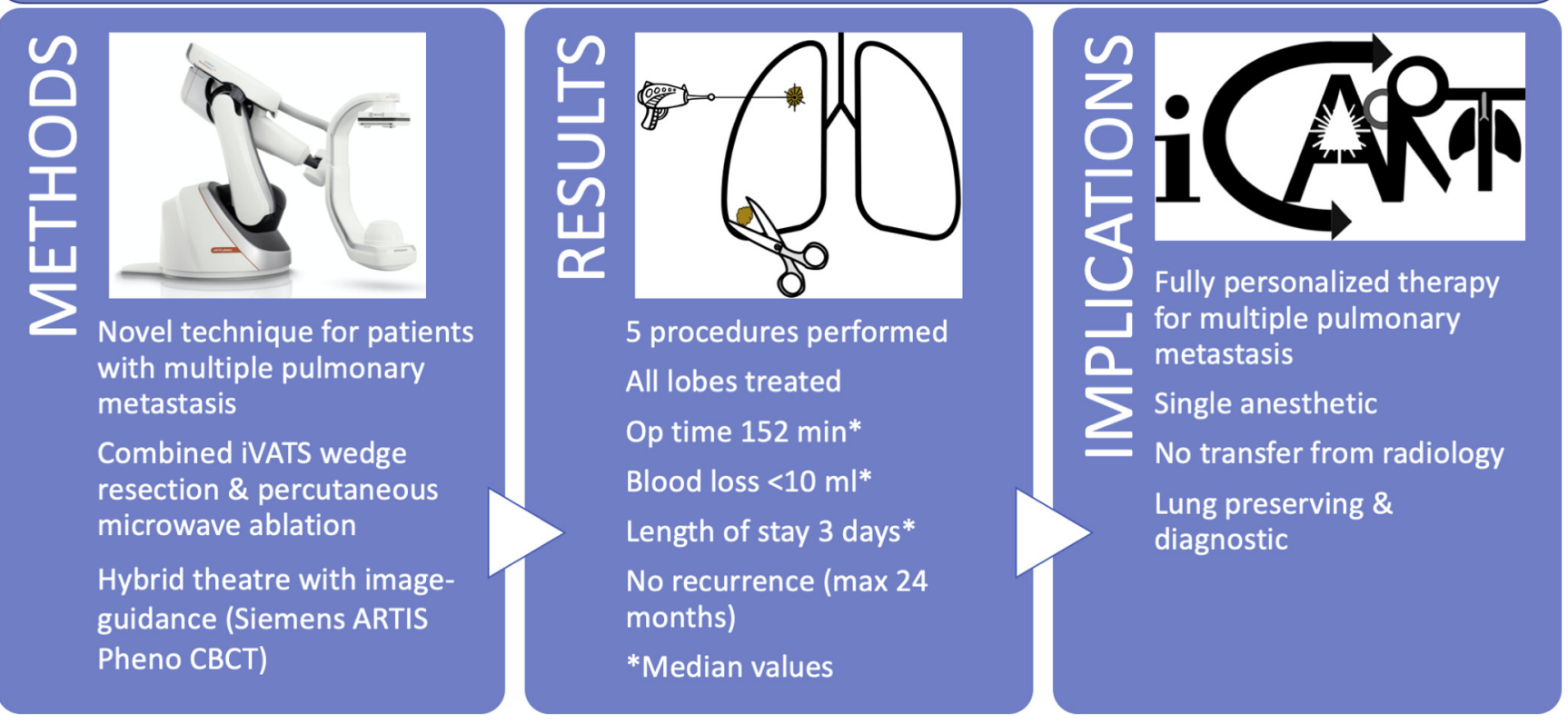

FIGURE 4. Combined percutaneous ablation and wire-assisted VATS wedge resection with intraoperative image guidance can be used for patients with multiple pulmonary nodules in a single anesthetic without the need to transfer from radiology to an operating theatre. This minimally invasive procedure provides a comprehensive treatment strategy for a wide range of nodule characteristics, the demand for which is likely to increase significantly with the expansion of lung cancer screening. 
many units advocate the use of 2 ablation probes where lesions exceed $3 \mathrm{~cm} .{ }^{20}$ The largest lesion ablated in this series was $24 \mathrm{~mm}$ (performed with a single probe), although larger lesions have been successful ablated in isolated procedures at our institution (unpublished data).

Another disadvantage of pMWA is that is does not provide tissue for histology. Combining with VATS wedge resection offers a diagnostic advantage. iVATS is a useful adaptation of conventional VATS wedge resection allowing localization of smaller, nonsolid nodules. ${ }^{9,21,22}$ It is particularly useful for lesions $<10 \mathrm{~mm}$ in diameter and GGOs or semisolid lesions where manual palpation by conventional VATS would be challenging or impossible. Our technique of coil localization clearly demonstrates the location of the lesion on entry into the chest. We then utilize the wire as a retractor to gently present the lesion to the stapling device and facilitate easy resection via a uniportal VATS approach. It could be argued that a skilled surgeon may be able to identify even the deepest and smallest of nodules that iCART aims to treat. However, palpation of such nodules, particularly GGOs, can be extremely challenging and this is where iCART may be especially useful and effective. Similarly, resection of multiple small, deep nodules will likely require a thoracotomy and cutting down through lung tissue with potential risks of slower postoperative recovery and prolonged air leak.

Pneumothorax is a recognized complication of percutaneous ablation occurring in $15 \%$ to $33 \%$ of cases. ${ }^{23}$ Risk factors for pneumothorax include lower lobe location of the nodule, older age, smaller tumor size, pulmonary emphysema, and the trajectory length through aerated lung. ${ }^{24}$ Other complications include intrapulmonary bleeding, pleural effusion, and lower respiratory tract infection. ${ }^{16,25}$ Pneumothorax occurred in $40 \%$ of the cases in our series. Clinically, this is of little concern as an iatrogenic pneumothorax and chest tube insertion is performed during iVATS. However, pneumothorax occurring before wire localization of the lesion for iVATS may be troublesome and prevented successful localization in 1 case. Subsequent to this, we have adopted 2 modifications to help minimize the risk of pneumothorax. Firstly, we use a positive end-expiratory pressure circuit to maintain the volume of the isolated lung and prevent its tendency to collapse away from the chest wall. Secondly, we leave the ablation probe in situ whilst performing wire-localization of the lesion for iVATS, because withdrawing the probe may increase the risk of transient air leak. Of note, we are able to successfully localize lesions in the presence of a pneumothorax, so their occurrence does not automatically indicate procedure failure. Preemptive chest tube insertion has been trialed in isolated pMWA/iVATS cases; however, this rendered placement of the ablation probe or guidewire more challenging, perhaps due to some loss of surface tension.
Establishing and running a hybrid operating room is expensive but is not mandatory for iCART. Ablation and insertion of localization wires can be performed in the radiology department (common practice in many institutions) and then the patient can be transferred to the operating room for resection of the localized lesions. However, we believe a more optimal treatment strategy (in terms of total procedure time, patient safety, and patient comfort) can be provided in a hybrid operating room. There is no need for the patient to be transferred (which in some institutions may be a considerable distance), with potential risks of anesthesia-related complications (or patient distress if awake), undetected expanding pneumothorax, and the risk of localization device dislodgement. A formal cost analysis was not an objective of this study and exact costings for the hybrid operating suite from our institutional management was not available. As an estimate, in 2019 to 2020 the mean cost to run an operating room in our institution was approximately $£ 22$ (US\$30)/minute, including salary and nonsalary costs (eg, overheads, depreciation, and facilities). The figure for running a hybrid operating suite is likely to be higher than this.

This study has a number of limitations. Our cohort is small, mainly because referral of suitable cases was infrequent in the early stages of implementation, partly due to lack of awareness of the emergence of this procedure. Similarly, the coronavirus disease 2019 pandemic began during the study period and reduced our capacity to perform these procedures. Typical length of stay following iCART was 2 to 3 days, which could safely be reduced with further experience with these patients during the postoperative period. Ultimately, we anticipate an overnight stay to be adequate for a majority of patients with chest tube removal and discharge on postoperative day 1 . Treatment of deep nodules close to the hilum remains a challenge. Endobronchial therapy may ultimately provide a solution to this but such techniques remain experimental. ${ }^{26,27}$ Similarly, laser metastatectomy by VATS is reported and could be used as an alternative to wedge resection to further minimize lung tissue loss. ${ }^{28}$ Lymphadenectomy as part of pulmonary metastatectomy is not routinely performed at our institution but strongly predicts prognosis and incorporation into iCART must be considered with further refinement of the technique. ${ }^{29}$ Finally, this study only included patients with nodules highly suspicious for metastatic disease; however, in the context of multiple pulmonary nodules, multiple GGOs are a more common scenario. Early evidence gleaned during the past few years suggests that pMWA may be a safe and feasible management strategy for patients with multiple GGOs. ${ }^{30}$ Because the etiology of GGOs are so varied, combining with resection may provide a particular advantage in subsequent decision making regarding further completion surgery (eg, anatomical lung resection), medical therapy, or interval surveillance imaging. Similarly, 
thermal ablation is emerging as an alternative to stereotactic radiation therapy in the treatment of stage 1 non-small cell lung cancer suggesting that the application of iCART may expand to nonmetastatic pulmonary nodules in future. ${ }^{3}$

\section{CONCLUSIONS}

iCART provides a minimally invasive and comprehensive personalized therapy for patients with multiple pulmonary metastases under a single general anesthetic. Further refinements and recruitment of a larger series are in progress, but early experience suggests the procedure is feasible and safe. In the United States, increased frequency of computed tomography chest imaging in adults following the implementation of lung cancer screening has caused the detection rate of lung nodules to increase dramatically from 3.9 to 6.6 per 1000 person-years. ${ }^{32}$ Similarly, with the introduction of thermal ablation into early lung cancer treatment, we anticipate the need for iCART and similar techniques to increase in the coming decade.

\section{Conflict of Interest Statement}

The authors reported no conflicts of interest.

The Journal policy requires editors and reviewers to disclose conflicts of interest and to decline handling or reviewing manuscripts for which they may have a conflict of interest. The editors and reviewers of this article have no conflicts of interest.

The authors thank Dr Donna Winderbank-Scott, consultant neonatologist, University Hospital Southampton, Southampton, United Kingdom, for designing the iCART logo.

\section{References}

1. Golfinopoulos V, Salanti G, Pavlidis N, Ioannidis JP. Survival and diseaseprogression benefits with treatment regimens for advanced colorectal cancer: a meta-analysis. Lancet Oncol. 2007;8:898-911.

2. Singer EA, Gupta GN, Srinivasan R. Targeted therapeutic strategies for the management of renal cell carcinoma. Curr Opin Oncol. 2012;24:284-90.

3. Pastorino U, Buyse M, Friedel G, Ginsberg RJ, Girard P, Goldstraw P, et al. Longterm results of lung metastasectomy: prognostic analyses based on 5206 cases. $J$ Thorac Cardiovasc Surg. 1997;113:37-49.

4. Li G, Xue M, Chen W, Yi S. Efficacy and safety of radiofrequency ablation for lung cancers: a systematic review and meta-analysis. Eur J Radiol. 2018;100: 92-8.

5. Dupuy DE. Microwave ablation compared with radiofrequency ablation in lung tissue-is microwave not just for popcorn anymore? Radiology. 2009;251:617-8.

6. Smith SL, Jennings PE. Lung radiofrequency and microwave ablation: a review of indications, techniques and post-procedural imaging appearances. Br J Radiol. 2015;88:20140598.

7. Liu B-D, Zhi X-Y. Expert consensus on image-guided radiofrequency ablation of pulmonary tumors-2015 edition. J Thorac Dis. 2015;7:E148-59.

8. Gill RR, Zheng Y, Barlow JS, Jayender J, Girard EE, Hartigan PM, et al. Imageguided video assisted thoracoscopic surgery (iVATS) - phase I-II clinical trial. $J$ Surg Oncol. 2015;112:18-25.

9. Gill RR, Barlow J, Jaklitsch MT, Schmidlin EJ, Hartigan PM, Bueno R. Imageguided video-assisted thoracoscopic resection (iVATS): translation to clinical practice-real-world experience. J Surg Oncol. 2020;121:1225-32.

10. Lencioni R, Crocetti L, Cioni R, Suh R, Glenn D, Regge D, et al. Response to radiofrequency ablation of pulmonary tumours: a prospective, intention-totreat, multicentre clinical trial (the RAPTURE study). Lancet Oncol. 2008;9: $621-8$.
11. Matsui Y, Hiraki T, Gobara H, Iguchi T, Fujiwara H, Nagasaka T, et al. Long-term survival following percutaneous radiofrequency ablation of colorectal lung metastases. J Vasc Interv Radiol. 2015;26:303-10.

12. de Baère T, Aupérin A, Deschamps F, Chevallier P, Gaubert Y, Boige V, et al. Radiofrequency ablation is a valid treatment option for lung metastases: experience in 566 patients with 1037 metastases. Ann Oncol. 2015;26:987-91.

13. Shiono S, Ishii G, Nagai K, Yoshida J, Nishimura M, Murata Y, et al. Predictive factors for local recurrence of resected colorectal lung metastases. Ann Thorac Surg. 2005;80:1040-5.

14. Inoue M, Ohta M, Iuchi K, Matsumura A, Ideguchi K, Yasumitsu T, et al. Benefits of surgery for patients with pulmonary metastases from colorectal carcinoma. Ann Thorac Surg. 2004;78:238-44.

15. Shiono S, Okumura T, Boku N, Hishida T, Ohde Y, Sakao Y, et al. Outcomes of segmentectomy and wedge resection for pulmonary metastases from colorectal cancer. Eur J Cardiothorac Surg. 2017;51:504-10.

16. Yang X, Ye X, Zhang L, Geng D, Du Z, Yu G, et al. Microwave ablation for lung cancer patients with a single lung: clinical evaluation of 11 cases. Thorac Cancer. 2018;9:548-54.

17. Chan VO, McDermott S, Malone DE, Dodd JD. Percutaneous radiofrequency ablation of lung tumors: evaluation of the literature using evidence-based techniques. J Thorac Imaging. 2011;26:18-26.

18. de Baère T, Palussière J, Aupérin A, Hakime A, Abdel-Rehim M, Kind M, et al. Midterm local efficacy and survival after radiofrequency ablation of lung tumors with minimum follow-up of 1 year: prospective evaluation. Radiology. 2006;240: 587-96.

19. Gillams AR, Lees WR. Radiofrequency ablation of lung metastases: factors influencing success. Eur Radiol. 2008;18:672-7.

20. Yamakado K, Inoue Y, Takao M, Takaki H, Nakatsuka A, Uraki J, et al. Longterm results of radiofrequency ablation in colorectal lung metastases: single center experience. Oncol Rep. 2009;22:885-91.

21. Chao Y-K, Wen C-T, Fang H-Y, Hsieh M-J. A single-center experience of 100 image-guided video-assisted thoracoscopic surgery procedures. J Thorac Dis. 2018;10(Suppl 14):S1624-30.

22. Fang H-Y, Chao Y-K, Hsieh M-J, Wen CT, Ho PH, Tang WJ, et al. Image-guided video-assisted thoracoscopic surgery for small ground glass opacities: a case series. J Vis Surg. 2017;3:142.

23. Hiraki T, Tajiri N, Mimura H, Yasui K, Gobara H, Mukai T, et al. Pneumothorax, pleural effusion, and chest tube placement after radiofrequency ablation of lung tumors: incidence and risk factors. Radiology. 2006;241:275-83.

24. Gillams AR, Lees WR. Analysis of the factors associated with radiofrequency ablation-induced pneumothorax. Clin Radiol. 2007;62:639-44.

25. Zheng A, Wang X, Yang X, Wang W, Huang G, Gai Y, et al. Major complications after lung microwave ablation: a single-center experience on 204 sessions. Ann Thorac Surg. 2014;98:243-8.

26. Ferguson JS, Henne E. Bronchoscopically delivered thermal vapor ablation of human lung lesions. J Bronchology Interv Pulmonol. 2019;26:108-13.

27. Yuan HB, Wang XY, Sun JY, Xie FF, Zheng XX, Tao GY, et al. Flexible bronchoscopy-guided microwave ablation in peripheral porcine lung: a new minimally-invasive ablation. Transl Lung Cancer Res. 2019;8:787-96.

28. Meyer C, Bartsch D, Mirow N, Kirschbaum A. Video-assisted laser resection of lung metastases-feasibility of a new surgical technique. Thorac Cardiovasc Surg. 2017;65:382-6

29. Veronesi G, Petrella F, Leo F, Solli P, Maissoneuve P, Galetta D, et al. Prognostic role of lymph node involvement in lung metastasectomy. J Thorac Cardiovasc Surg. 2007;133:967-72.

30. Huang G, Yang X, Li W, Wang J, Han X, Wei Z, et al. A feasibility and safety study of computed tomography-guided percutaneous microwave ablation: a novel therapy for multiple synchronous ground-glass opacities of the lung. Int J Hyperthermia. 2020;37:414-22.

31. Uhlig J, Ludwig JM, Goldberg SB, Chiang A, Blasberg JD, Kim HS. Survival rates after thermal ablation versus stereotactic radiation therapy for stage 1 non-small cell lung cancer: a National Cancer Database Study. Radiology. 2018;289:862-70.

32. Gould MK, Tang T, Liu IL, Lee J, Zheng C, Danforth KN, et al. Recent trends in the identification of incidental pulmonary nodules. Am J Respir Crit Care Med. 2015; 192:1208-14.

Key Words: pulmonary nodule, pulmonary metastasis, hybrid surgery, image-guided surgery, microwave ablation, wedge resection, metastatectomy 